\title{
Decoupled Sliding Mode Control for an Induction Motor
}

\author{
Ibrahim .S. Zeidan \\ Computers and System \\ Engineering, Zagazig \\ University, Egypt
}

\author{
Sabry .F.Saraya \\ Computers and System \\ Engineering, Mansoura \\ University, Egypt
}

\author{
Ghada Kareem \\ Higher Technological Institute, \\ Tenth of Ramadan City, Egypt
}

\begin{abstract}
This paper represents a decoupled control strategy using sliding surface based on sliding mode controller for speed control of induction motor . The decoupled method provides a simple way to achieve asymptotic stability for induction motor .A strategy of sliding mode control is used, the decoupling method in this study uses two sliding mode controller for flux and speed. Then it compared by using PI controller which control flux and speed of the motor. Both controllers are simulated using SIMULINK .Simulation results are presented the effectiveness and good performance of the decoupling sliding mode control by considering the effects of the variations of the load torque.
\end{abstract}

\section{General Terms}

Robust control, induction motor

\section{Keywords}

Sliding mode control, Decoupling control, field oriented control, Variable structure systems (VSS)

\section{INTRODUCTION}

One of the most popular AC motors is Induction motor, it makes huge advances in electronic, microprocessor technology and industrial requirement, so it uses in many control approaches. However one of the most difficulties of induction motor is how to control it because of their nonlinear dynamics [1].Variable structure control theory is updated in the recent years for controlling induction motor .The sliding mode control is the main phenomenon in VSS which is mainly a discontinuous control technique [2]. The main objective of sliding mode control is to force the system to a specific surface called sliding surface (fig 2) [3-4].The strategy of variable structure control in using the sliding mode gives much attention in the recent years for controlling induction motors [5-7]. Decoupled torque and flux is achieved in Field orientation control (FOC) or vector control of induction machine [8-10]. The stator current can be resolved into two parts that is the main idea of the FOC; the first one controls the torque production and the second controls the flux. Thus the torque and flux would be controlled independently. However complete decoupling was not yet achieved [11-14]. In this paper, two different methods used to control induction motor .The first method we use two P-I controllers which are used for controlling speed and rotor flux .The decoupling of the rotor flux and rotor speed is shown in Simulation results, when the load changes, it is effected in torque response and motor speed. In the second method, sliding mode controllers for speed and flux are applied. The compared of the two methods are shown in the result.

\section{MODEL DESCRIPTION OF INDUCTION MOTOR}

The following block diagram of the induction motor (foc) with sliding mode speed and flux controller is shown in fig (1). The main components of block diagram are three controllers, the first one is flux controller, the second is speed controller and the third is current controller which is hysteresis control. The main purpose of the shown block diagram is indicated are two sliding mode controllers used for speed and flux. The inputs to the decoupling controller are the Outputs of flux and speed controller, and the input of the current controller is the output of the decoupling. Two methods are used for controlling induction motor; the first method is controlling flux and speed by using two PI controllers. The second method is controlling flux and speed by using sliding mode controllers [9]. The mathematical model of induction motor using speed and flux controllers is discussed below.

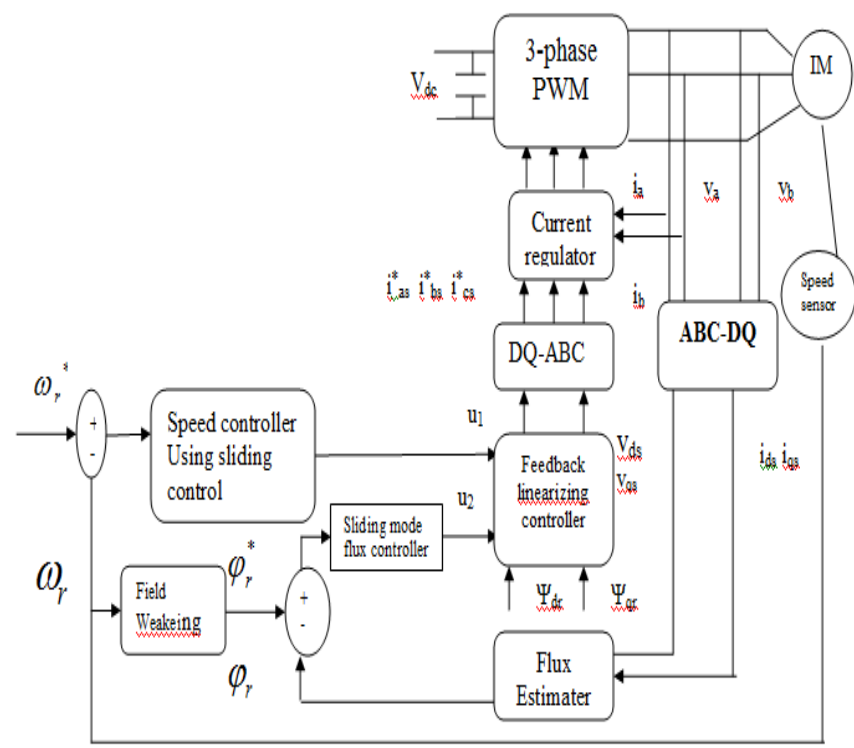

Fig.2 block diagram of sliding mode speed and flux controller 


\section{MATHEMATICAL MODEL DESCRIPTION OF INDUCTION MOTOR}

Induction motor dynamic equations is expressed in the $\mathrm{d}-\mathrm{q}$ coordinates by the following equations as [9],[15]

$i_{d s}^{\cdot}=\frac{1}{\alpha L_{s}}\left(R_{s}+\frac{L_{m}^{2}}{L_{r}^{2}} R_{r}\right) i_{d s}+\frac{1}{\alpha L_{s}} \frac{L_{m} R_{r}}{L_{r}^{2}} \varphi_{d r}+\frac{p L_{m}}{\alpha L_{s} L_{r}} \omega_{r} \varphi_{q r}+\frac{V_{d s}}{\alpha L_{s}}$

$\mathrm{i}_{\mathrm{qs}}^{\cdot}=\frac{1}{\alpha L_{s}}\left(R_{s}+\frac{L_{m}^{2}}{L_{r}^{2}} R_{r}\right) i_{q s}+\frac{1}{\alpha L_{s}} \frac{L_{m} R_{r}}{L_{r}^{2}} \varphi_{q r}-\frac{p L_{m}}{\alpha L_{s} L_{r}} \omega_{r} \varphi_{d r}+\frac{V_{q s}}{\alpha L_{s}}$

$\varphi_{\mathrm{dr}}^{\cdot}=-\frac{R_{r}}{L_{r}} \varphi_{d r}-p \omega_{r} \varphi_{q r}+\frac{L_{m} R_{r}}{L_{r}} i_{d s}$

$\varphi_{\mathrm{qr}}^{\cdot}=-\frac{R_{r}}{L_{r}} \varphi_{q r}+p \omega_{r} \varphi_{d r}+\frac{L_{m} R_{r}}{L_{r}} i_{q s}$

$\omega_{\mathrm{r}}^{\cdot}=-\frac{\mathrm{B}}{\mathrm{J}} \omega_{r}+\frac{1}{J}\left(T_{e}-T_{i}\right)$

Where $\varphi_{d r}, \varphi_{q r}$ are the rotor flux, $\alpha=\left(1-\frac{\mathrm{L}_{\mathrm{m}}^{2}}{\mathrm{~L}_{\mathrm{s}} L_{r}}\right)$ is the leakage factor, $i_{d s}, i_{q s}$ are the stator currents, and control stator voltage is defined by $V_{d s}, V_{q s}, L_{r}, L_{s}$ are rotor and stator inductances and $R_{r}, R_{s}$ are rotor and stator resistances and magnetizing inductance is $\mathrm{L}_{\mathrm{m}}, \omega_{r}$ is the motor speed, and $\mathrm{p}$ is the number of pole pairs [9] .

The electromagnetic torque is represented by

$T_{e}=K\left(\varphi_{d r} i_{q s}-\varphi_{q r} i_{d s}\right)$

Where $K=\frac{3 p L_{m}}{2 L_{r}}$, from equation (5), (6) the rotor speed state equation can be written as follow

$\omega_{r}^{\cdot}=-\frac{B}{J} \omega_{r}+\frac{1}{J} K\left(\varphi_{d r} i_{q s}-\varphi_{q r} i_{d s}\right)-\frac{T_{L}}{J}$

From above we can deduce the state space equation of induction motor as below

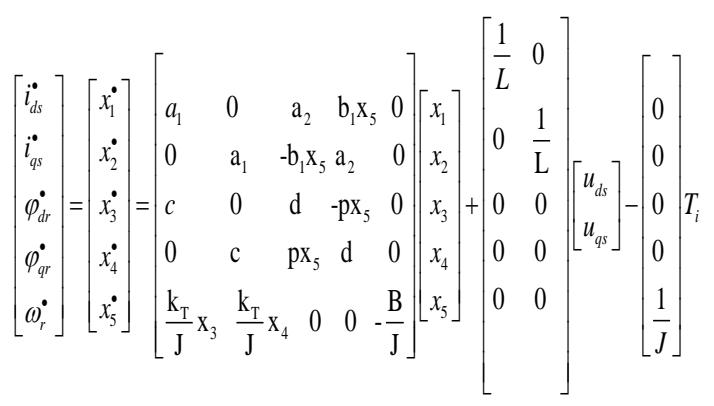

Where, $a_{1}=\frac{1}{\alpha L_{s}}\left(R_{s}+\frac{L_{m}^{2}}{L_{m}^{2}} R_{r}\right), a_{2}=\frac{1}{\alpha L_{s}} \frac{L_{m} R_{r}}{L_{r}^{2}}$

$$
b_{1}=\frac{p L_{m}}{\alpha L_{S} L_{r}}, c=\frac{R_{r}}{L_{r}}, d=\frac{L_{m} R_{r}}{L_{r}}
$$

\section{DECOUPLED CONTROL}

The induction motor in field oriented can be controlled by decoupling the rotor speed and rotor flux to obtain a DC motor like behavior. The rotor speed and rotor flux are controlled.

$Y=\left[\omega_{r}, \varphi_{r}\right]$

The rotor flux is considered as

$\varphi_{\mathrm{r}}^{2}=\varphi_{\mathrm{dr}}^{2}+\varphi_{q r}^{2}$

The derivative of equation (10) is

$\varphi_{r}^{\cdot}=\frac{1}{\varphi_{r}}\left[\varphi_{d r} \dot{\varphi_{d r}}+\varphi_{q r} \dot{\varphi}_{q r}^{\cdot}\right]$

By substituting from equation (3) and (4) into equation (11) we can find that

$\dot{\varphi_{r}}=\frac{1}{\varphi_{r}}\left[\varphi_{d r}\left(\frac{R_{r}}{L_{r}} \varphi_{d r}-p \omega_{r} \varphi_{q r}+\frac{L_{m} R_{r}}{L_{r}} i_{d s}\right)+\varphi_{q r}\left(\frac{R_{r}}{L_{r}} \varphi_{q r}-p \omega_{r} \varphi_{d r}+\frac{L_{m} R_{r}}{L_{r}} i_{q s}\right)\right]$

From above we will obtain rotor flux state equation as below

$\dot{\varphi_{r}}=-\frac{R_{r}}{L_{r}} \varphi_{r}+\frac{L_{m} R_{r}}{L_{r} \varphi_{r}}\left(i_{d r} \varphi_{d r}+i_{q s} \varphi_{q r}\right)$

The flux and speed of rotor is described by the state equations (7) and (13). Which are controlled by $i_{d s}$ and $i_{q s}$, the coupled system is obtained, The coupled system is converted to decoupled system by taking a new control input, consider $\mathrm{u}_{1}$ and $\mathrm{u}_{2}$ two new control input, The equations of uncoupled system can be written as below [18] .

$\dot{\varphi_{r}}=-\frac{R_{r}}{L_{r}} \varphi_{r}+\frac{L_{m} R_{r}}{L_{r}} u_{1}$

$\dot{\omega}_{r}^{\circ}=-\frac{B}{J} \omega_{r}+\frac{1}{J} K u_{2}-\frac{T_{L}}{J}$

we can deduce the control inputs from the above equations as below

$u_{1}=\frac{1}{\varphi_{r}}\left(\varphi_{d r} i_{d s}+\varphi_{q r} i_{q s}\right)$

$\mathrm{u}_{2}=\left(\varphi_{d r} i_{q s}-\varphi_{q r} i_{d s}\right)$

Deducing the stator current from the above equation

$i_{d s}=\frac{\varphi_{d r}}{\varphi_{r}} u_{1}-\frac{\varphi_{q r}}{\varphi_{r}^{2}} u_{2}$

$i_{q s}=\frac{\varphi_{q r}}{\varphi_{r}} u_{1}+\frac{\varphi_{d r}}{\varphi_{r}^{2}} u_{2}$

The decoupling controller of induction is given by the above equations [9]. 


\section{SLIDING MODE CONTROLLER}

The decoupled technique is used to reduce high dimensional design problem into lower dimensional independent subproblems .The sliding mode control algorithms is widely used because their robustness and capability of decoupling [17]

In sliding mode control ,construction of a suitable sliding surface so that the dynamic of the system confined to the sliding manifold produces a desired behavior .The dynamics of error $e(t)$ and its derivative $e^{\bullet}(t)$ are driven to the origin along the sliding line [3].

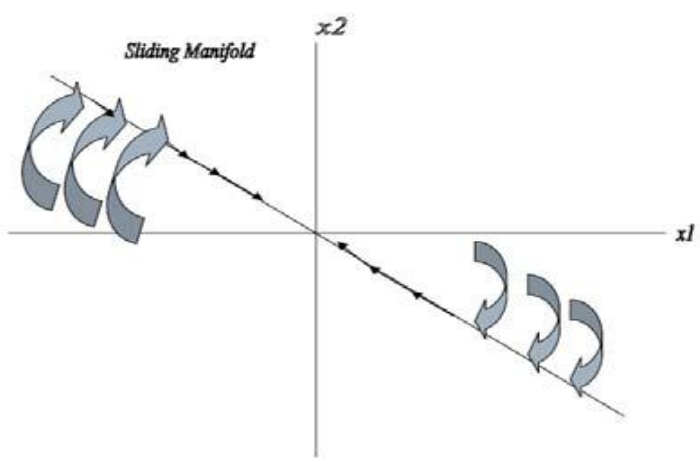

Fig.2 The sliding surface(s)

$$
s(t)=c e(t)+e^{\bullet}(t)
$$

Sliding mode controller for speed and flux are designed for the induction motor system as below,

$$
\begin{aligned}
& e_{1}=\omega_{r}{ }^{*}-\omega_{r} \\
& e_{2}=\varphi_{r}{ }^{*}-\varphi_{r}
\end{aligned}
$$

Let the sliding surfaces are defined as

$$
s_{1}=c_{1} e_{1}+e_{1}^{\bullet}, s_{2}=c_{2} e_{2}+e_{2}^{\bullet}
$$

The sliding mode control (SMC) speed controller is shown in fig 5 . The reference signal required in dq axis is calculated by using the PI block in the model. Fig (3) indicates the field oriented control, it contains a dq-abc block, this block performs the conversion of the $d q$ component of the currents into $a b c$ phase variables. The tracking error in speed equation (21) is calculated by SMC1. the block SMC2 represents the proposed sliding mode controller of the flux which is indicated in fig(6),fig(7), the SMC2 calculates the tracking error in flux Equation (22), when The reference currents for the motor is produced, the SMC surfaces forced the controlled system to slide on the sliding surfaces until it reach to the desired flux and speed. The desired speed will be faster response by selecting $C_{1}$ not large and this will reduce speed oscillations. Fig(4) indicates hysteresis current controller, one method of feed back current control is the hysteresis modulation where the motor current tracks the reference current within a hysteresis band, the principle operation of the hysteresis modulation is indicated in fig (4). The sinusoidal reference current of desired magnitude and frequency is generated by controller, which then is compared to the actual motor line current. If current exceeds the upper limit of the hysteresis band, the upper switch of the inverter arm is turned off and the lower switch is turned on. As a result the current begin to decay [16].

\section{SIMULATION RESULTS:}

Simulation has been carried out by using MATLAB/SIMULINK for 900rpm three phase induction motor which has parameters listed in table (1), The field oriented control induction motor (FOC IM) of Fig.(1) is run at sampling period $\mathrm{T}=2 \mathrm{e}-6 \mathrm{~s}$. In this section, the speed and the flux regulation performance of the proposed sliding mode is compared to that of the PI controller of the field oriented control IM. The performance is checked in terms of load torque variations. Fig (8-12) indicates the simulation results for a three phase induction motor, Fig (8) shows the sliding surfaces .It is noted that SMC forces the states of the system to move towards the sliding surfaces, then keeping the states slide on these surfaces and achieving the required performance. Fig (9) shows speed, torque and current using PI controller with load, fig (10) shows speed, torque and current using the SMC controller with load these results can be showed as the following:

At time $\mathrm{t}=0 \mathrm{~s}$, the speed set point $\omega_{r}^{*}$ is $500 \mathrm{rpm}$. As shown in the fig (9-b), the speed follows precisely the acceleration ramp. - At t $=0.5 \mathrm{~s}$, the full load torque is applied to the motor shaft while the motor speed is still ramping to its final value. This forces the electromagnetic torque to increase to the userdefined maximum value (1200 N.m) and then to stabilize at 820 N.m once the speed ramping is completed and the motor has reached $500 \mathrm{rpm}$.

At $\mathrm{t}=1 \mathrm{~s}$, the speed set point is changed to $0 \mathrm{rpm}$. The speed decreases down to $0 \mathrm{rpm}$ by following precisely the deceleration ramp even though the mechanical load is inverted abruptly, passing from 792 N.m to - 792 N.m,

At $\mathrm{t}=1.5 \mathrm{~s}$, the mechanical load reduced to $-1200 \mathrm{~N} . \mathrm{m}$. then the sudden torque changes is overcome by the SMC controller and the torque is stabilized at $-792 \mathrm{~N}$. m

High current $1500 \mathrm{~A}$ is begined by the motor, then the currents are decreased and sinusoidal waveform is stabilized with max $500 \mathrm{~A}$. all currents are decreased to max $480 \mathrm{~A}$ when the load torque is decreased to-792N.m at $1.5 \mathrm{~s}$

Fig (11) shows speed, torque and current using PI controller without load, fig (12) shows speed, torque and current using the SMC controller without load,, the speed response of Fig. (12) Shows no detected change in the rotor speed at these ranges, meaning that the sliding mode controller does well in rejecting the applied torque .Therefore the rotor speed is by now riding over the sliding trajectory and the controller is robust against change of the load torque.

\section{CONCLUSIONS}

This paper represents the design of control system for controlling the speed of induction motor using the decoupling sliding mode algorithm. The decoupled techniques provide a simple way to achieve asymptotic stability for induction motor. The performance of the system with PI controller and sliding mode controller are compared, the sliding mode controller results achieved effectiveness and robustness against the PI controller. Simulation results were presented good performances and robust against change in load torque and illustrate the effectiveness of the decoupling sliding mode control. 


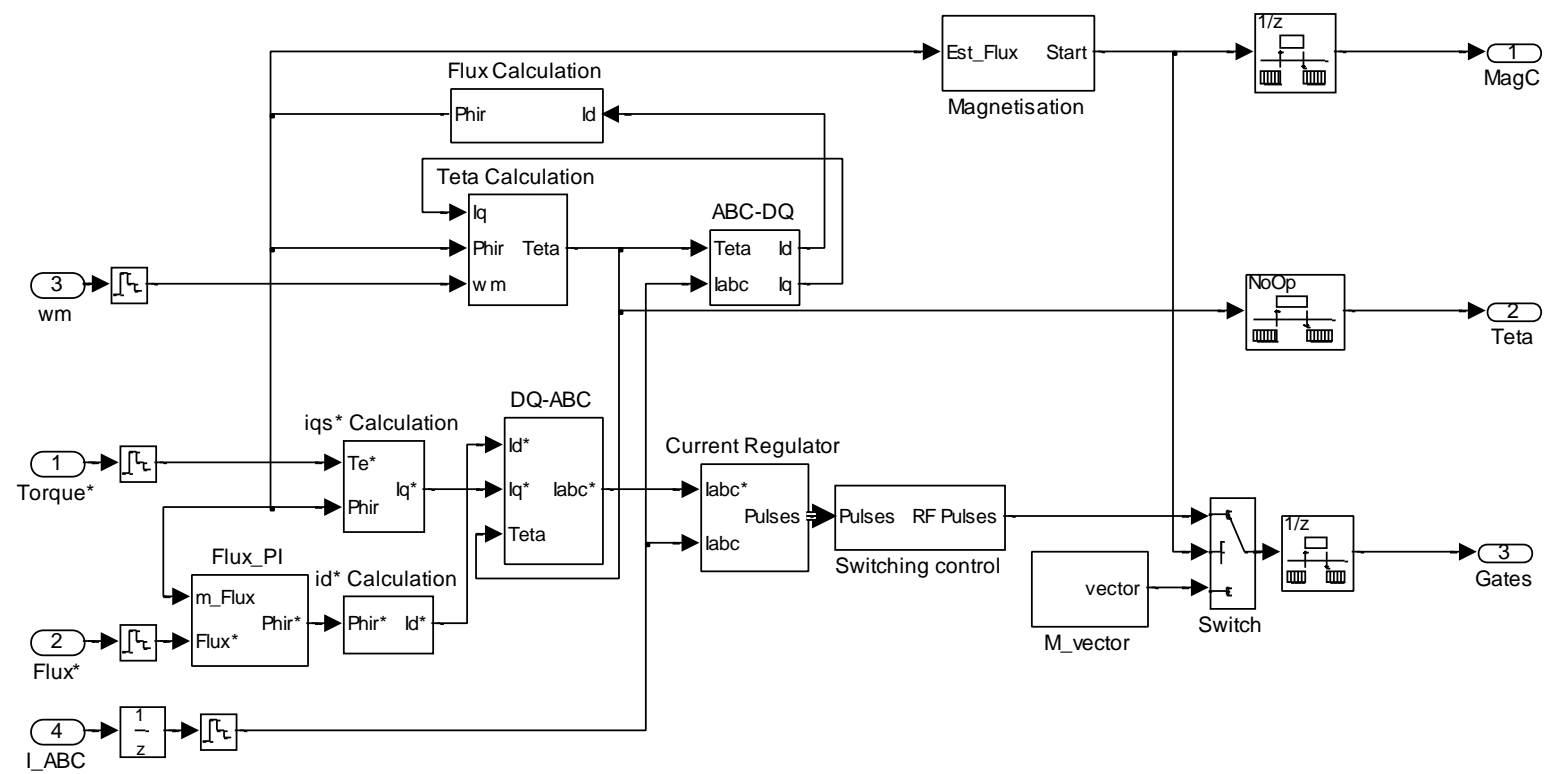

Fig.3 block of Field Oriented Control

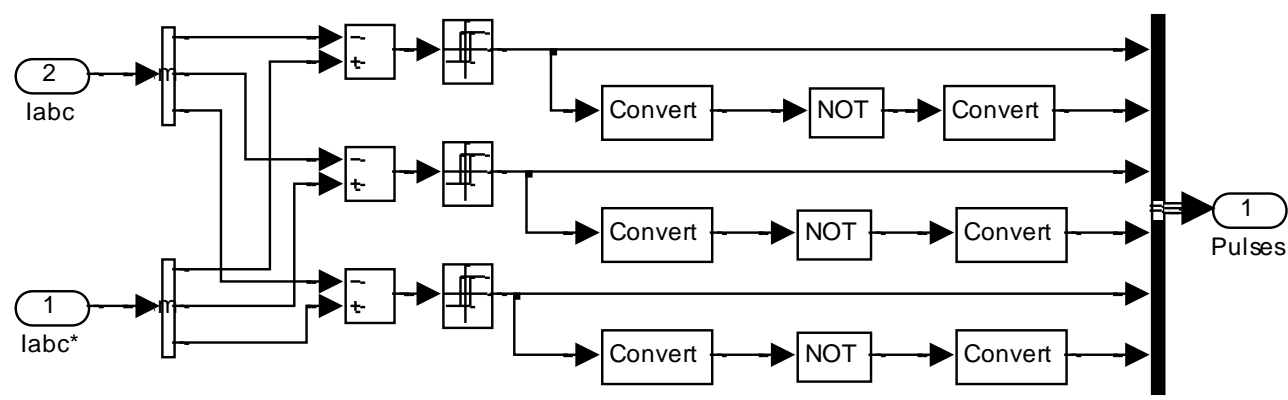

Fig.4 The simulink diagram of hysteresis current controller

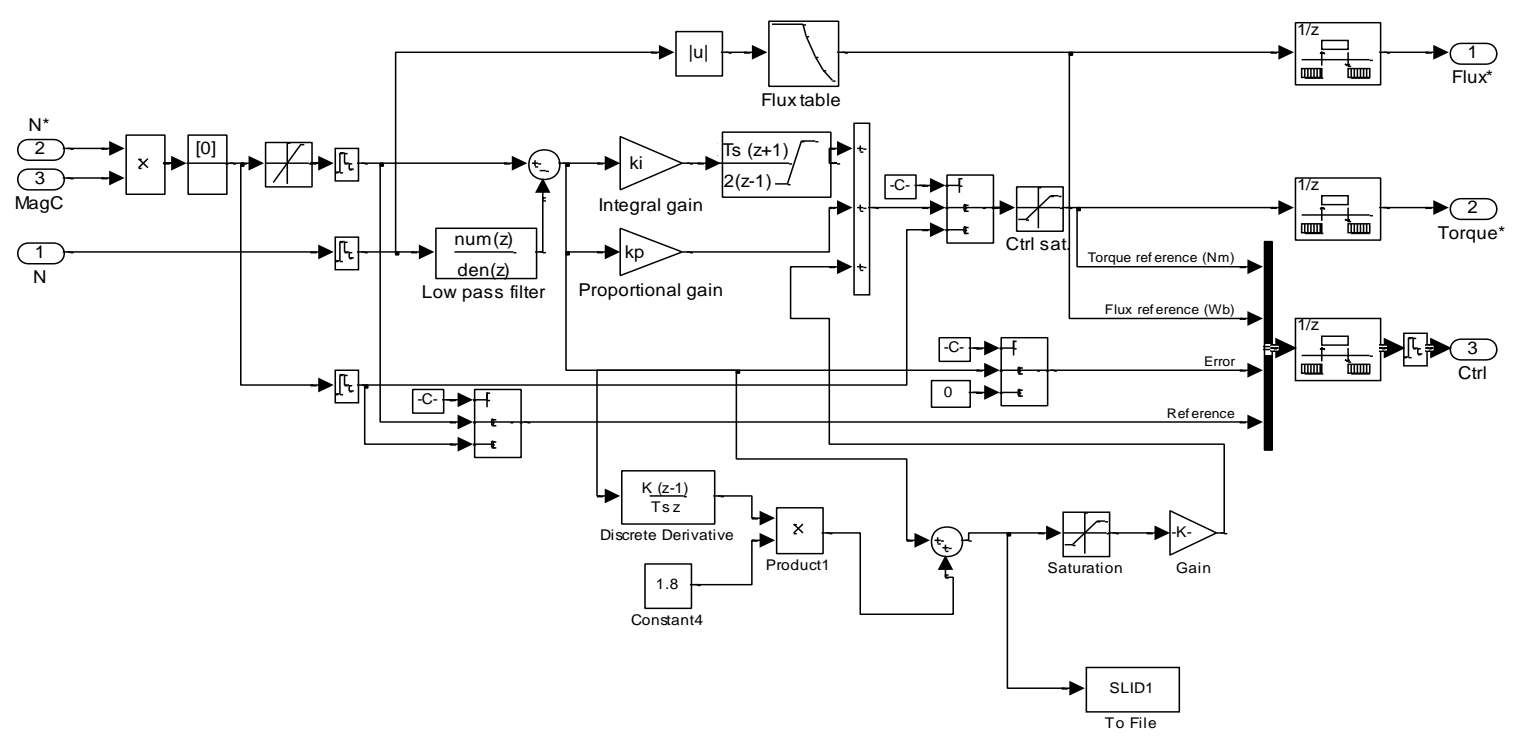

Fig.5 Simulink diagram of speed control of induction motor using SMC1 


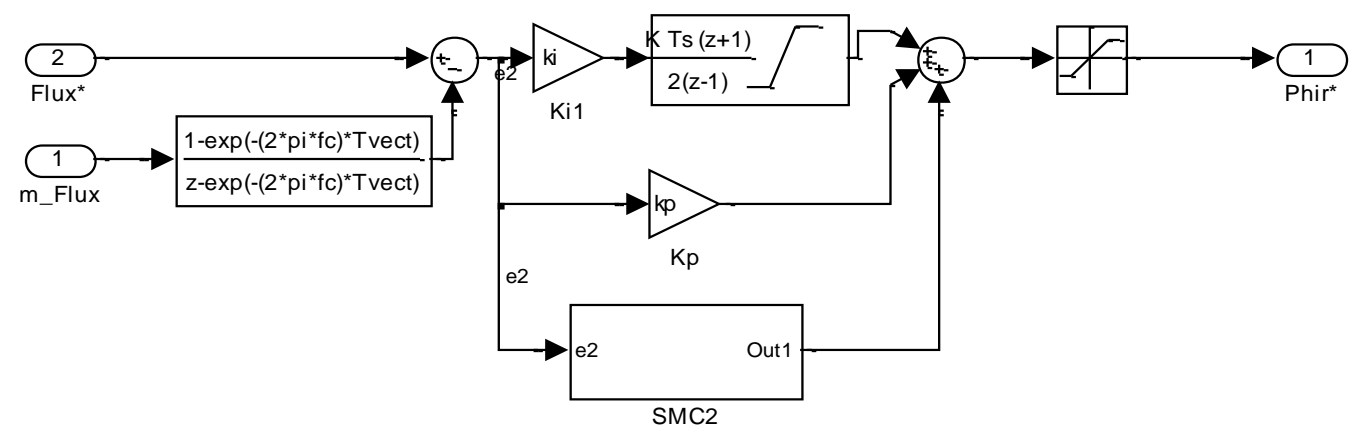

Fig.6 Simulink diagram of flux sliding mode

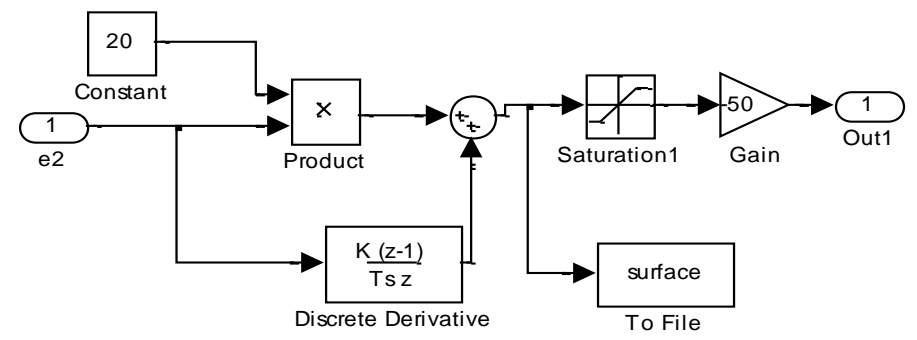

Fig.7 the SMC2 controller
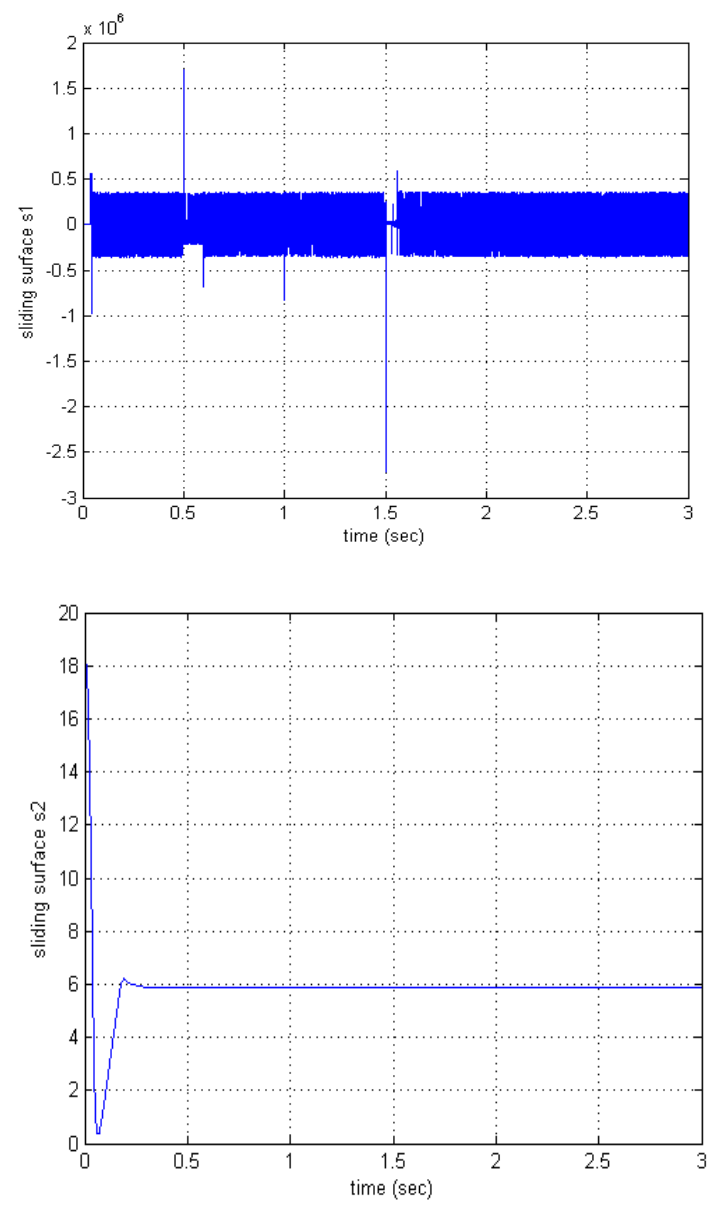

Fig.8 Sliding surfaces

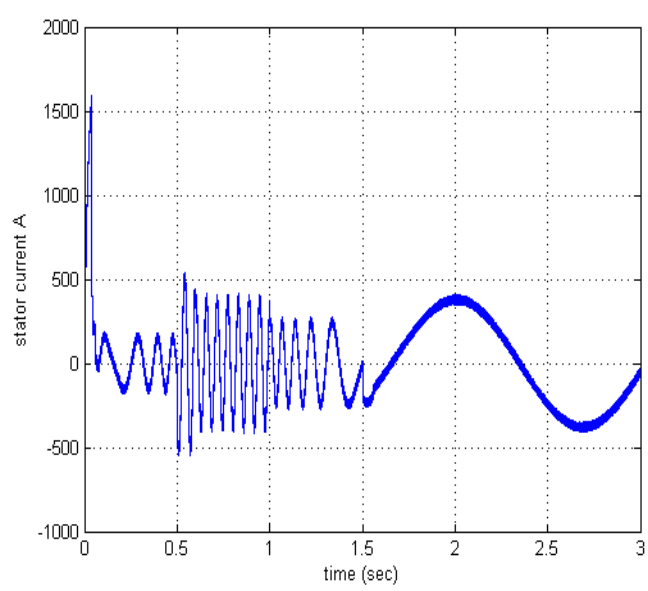

Fig (9-a)

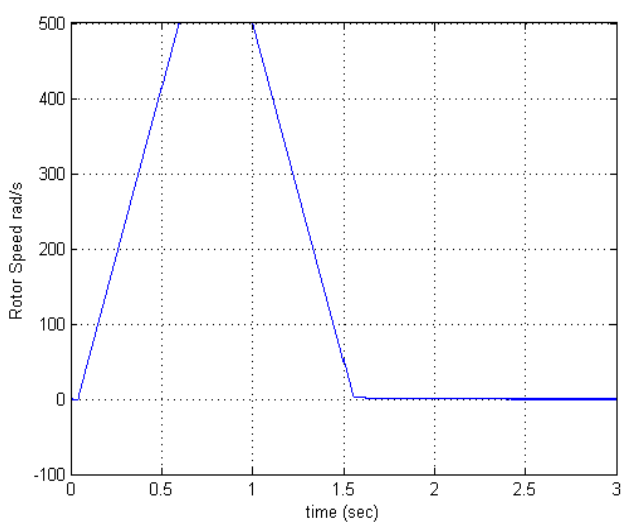

Fig (9-b) 


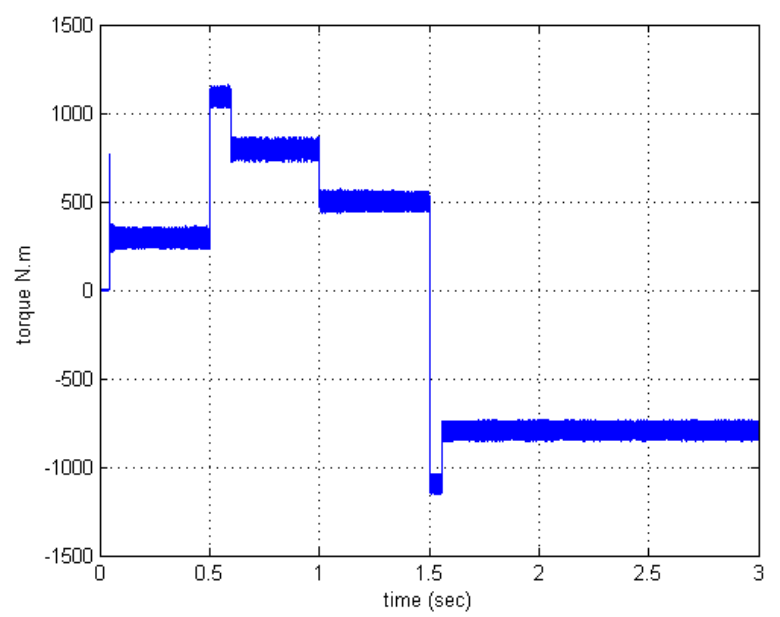

Fig (9-c)

Fig.9 simulation response with PI controllers with load

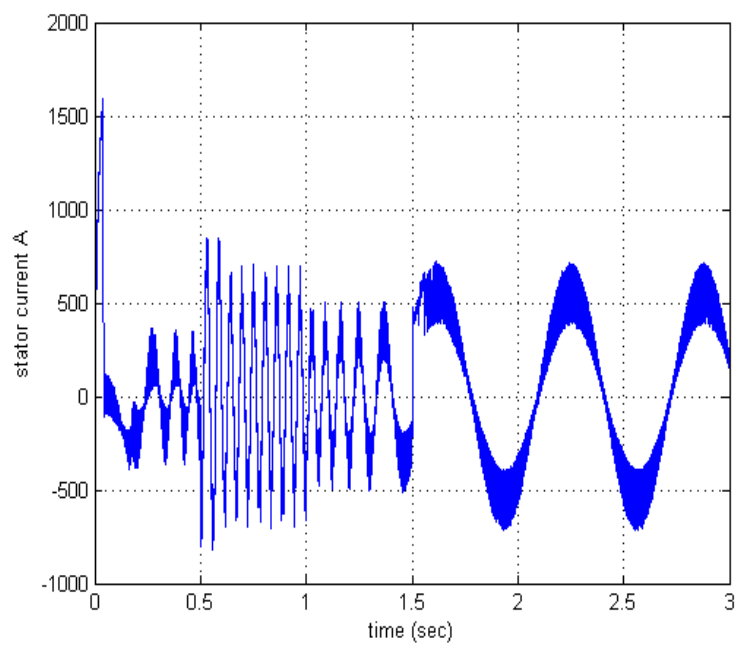

Fig (10-a)

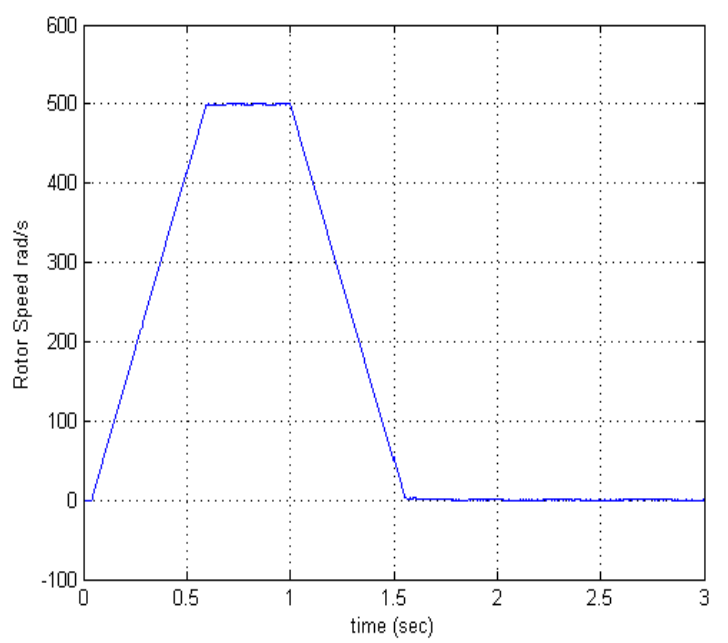

Fig (10-b)

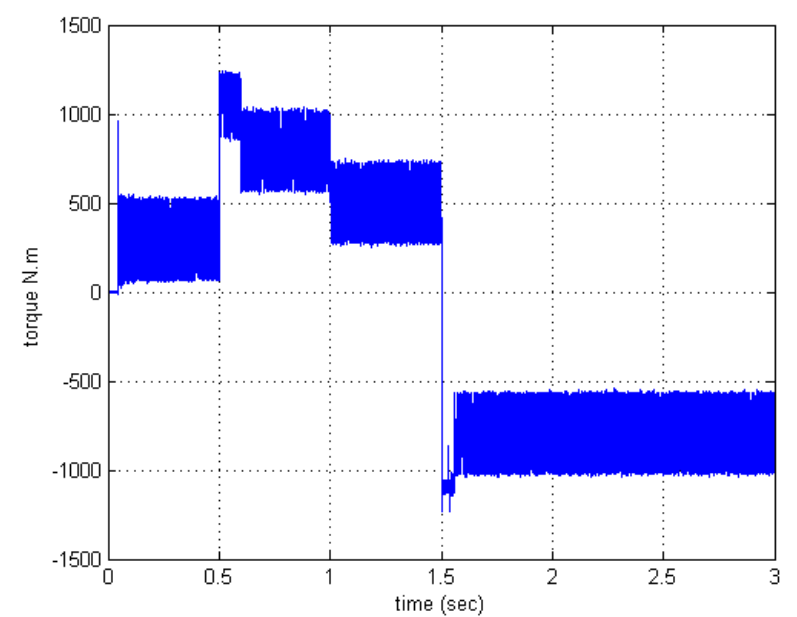

Fig (10-c)

Fig.10 simulation results with SMC with load

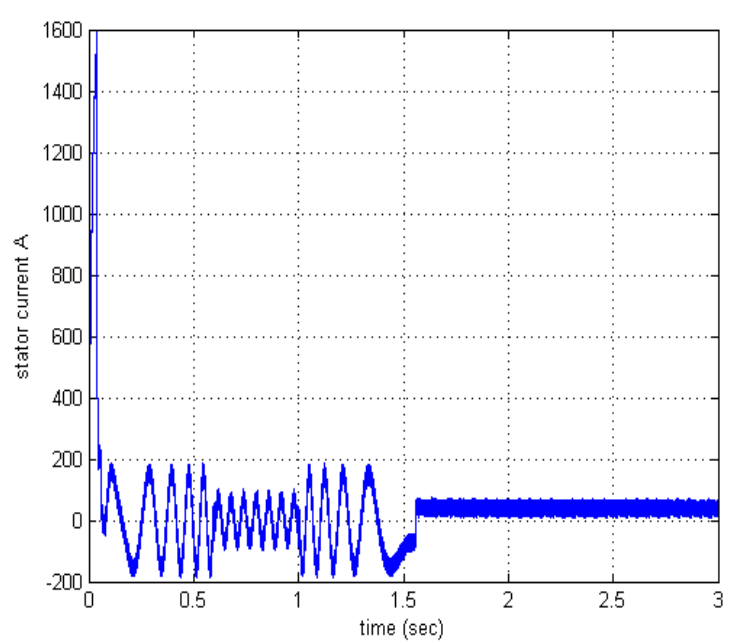

Fig (11-a)

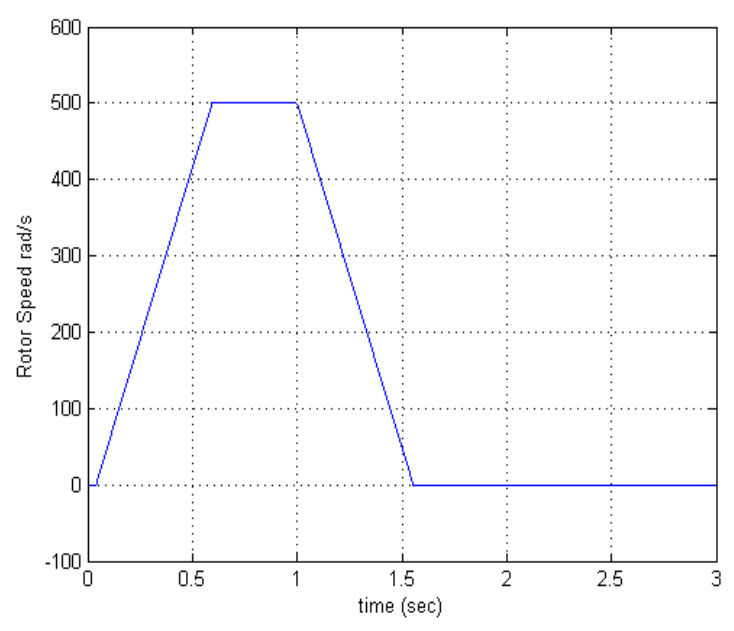

Fig (11-b) 


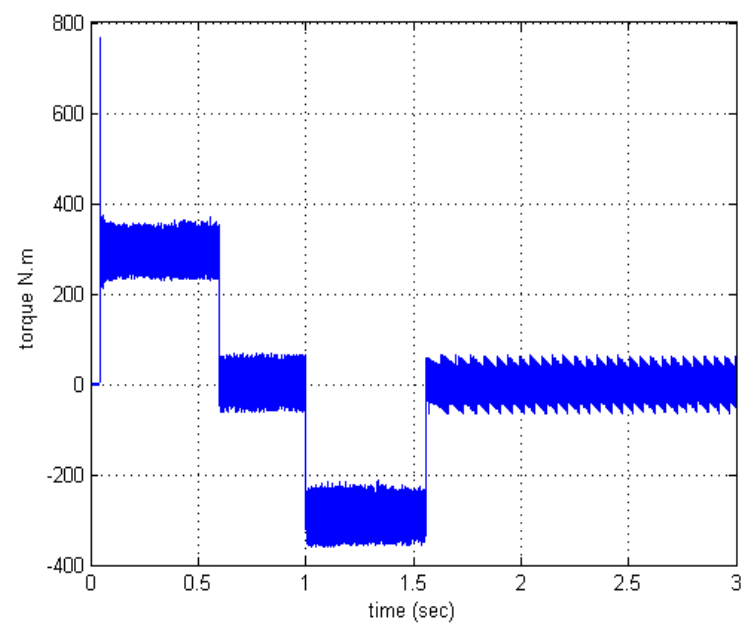

Fig (11-c)

Fig.11 simulation response with PI controllers with no load

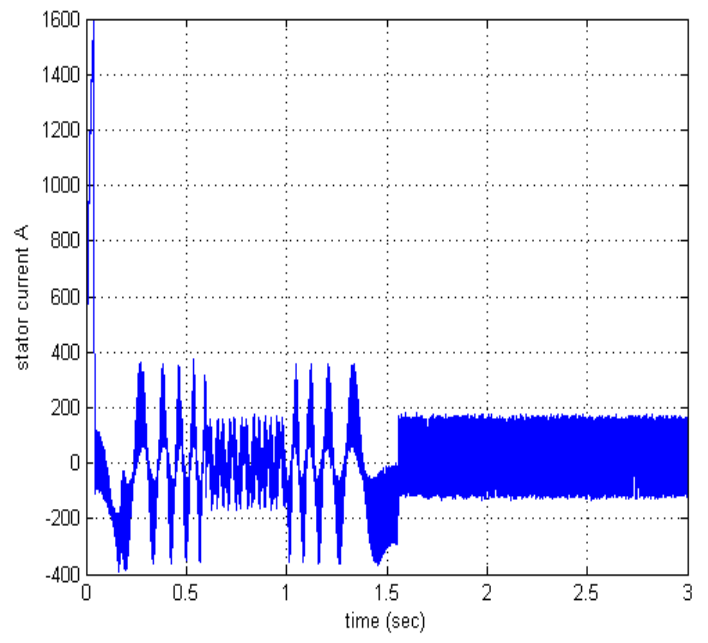

Fig (12-a)

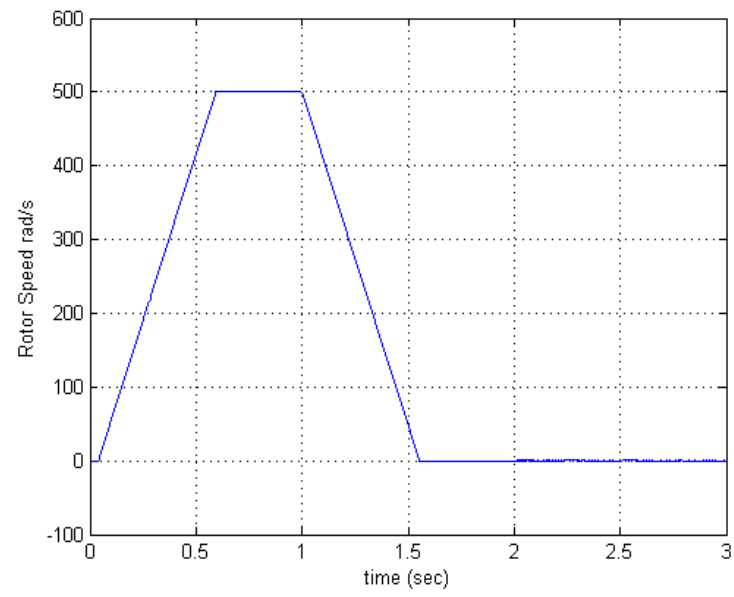

Fig (12-b)

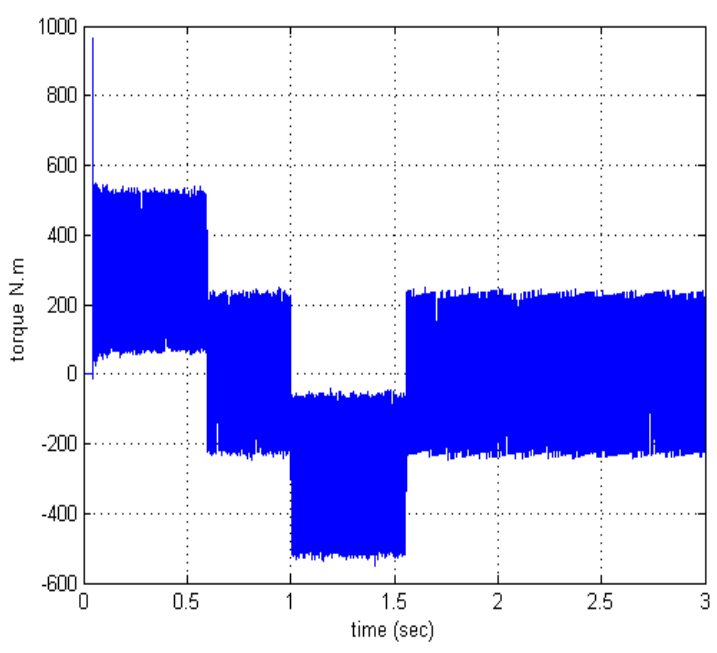

Fig (12-c)

Fig.12 simulation results with SMC with no load

Table 1. Ratings and Parameters of the Induction motor

\begin{tabular}{|l|l|}
\hline \multicolumn{1}{|c|}{ Three phase } & $\begin{array}{l}\text { 60Hz, 200HP, } \\
\text { 460volts, 900RPM }\end{array}$ \\
\hline Stator and Rotor Resistances & $\begin{array}{l}\mathrm{Rs}=0.0149 \Omega, \mathrm{Rr}= \\
0.0093 \Omega\end{array}$ \\
\hline Stator and Rotor self inductances & $\mathrm{Ls}=\mathrm{Lr}=0.3 \mathrm{mH}$ \\
\hline $\begin{array}{l}\text { Mutual inductance between stator } \\
\text { and rotor }\end{array}$ & $\mathrm{Lm}=10.46 \mathrm{mH}$ \\
\hline Moment of inertia & $\mathrm{J}=3.1 \mathrm{~kg} \cdot \mathrm{m} 2$ \\
\hline Coefficient of viscous friction & $\mathrm{B}=0.08 \mathrm{~N} . \mathrm{m} . \mathrm{s} / \mathrm{rad}$ \\
\hline
\end{tabular}

\section{REFERENCES}

[1] Bose, B. K., Modern Power Electronics and AC Drives, Prentice-Hall, N.J., 2002

[2] Utkin VI. "Variable Structure Systems with Sliding Mode: a survey" IEEE Trans Automat Control 1977; 22:212-

[3] Xinghuo Yu, Fellow, IEEE, and Okyay Kaynak, Fellow, IEEE2 "Sliding-Mode Control With Soft Computing: A Survey." IEEE TRANSACTIONS ON INDUSTRIAL ELECTRONICS, VOL. 56, NO. 9, SEPTEMBER 2009

[4] Wikfrid Perruquetti, Marcel Dekker "Sliding Mode Control in Engineering" 2002

[5] Do Th Hông Tham, D *ng Hoài Nghia ," Sliding Mode Control of Induction Motor" International Symposium on Electrical \& Electronics Engineering 2007 - Oct 24 252007 - HCM City, Vietnam

[6] Eman El-Gendy, Abdelhameed F. Ibrahim ,Sabry F. Saraya, Fayez. F. G. Areed " A Sliding Mode Controller for a Three Phase Induction Motor" 
[7] ABID, A. - MANSOURI, A. - AISSAOUI, A. BELABBES, B.: "Sliding Mode Application in Position Control of an Induction Machine", Journal of Electrical Engineering, Vol. 59, No. 6, pp. 322-327, 2008

[8] NOAMAN, N. M.: "Speed Control for IFOC Induction Machine with Robust Sliding Mode Controller", Asian Journal of Scientific Research 1(4): 324-337, 2008.

[9] Madhu Singh , K. B. Mohanty" Robust Control of a Feedback linearized Induction Motor through Sliding Mode" PEDES 2010

[10] Peng kang and zhao.jin "Neural Network Sliding Mode current Decoupled Control for Induction Motor Drive" information Technology Journal 9 (7) : (1440-1448) ,2010

[11] Rong-Jong Wai, Member, IEEE, and Kuo-Min Lin "Robust Decoupled Control of Direct Field-Oriented Induction Motor Drive" IEEE TRANSACTIONS ON INDUSTRIAL ELECTRONICS, VOL. 52, NO. 3, JUNE 2005837

[12] ERIK ETIEN_, SÉBASTIEN CAUET ,LAURENT RAMBAULT, GÉRARD CHAMPENOIS "Control of an Induction Motor Using Sliding Mode Linearization “ Int. J. Appl. Math. Comput. Sci., 2002, Vol.12, No.4, 523531
[13] Noaman, N. M.:" Robust Sliding Mode Control Based on IFOC Induction Machine With Speed Estimator" IJCCCE, VOL.7, NO.1, 2007

[14] Mrs. S. V. Jadhav,. M. Mohan Krishna Reddy, B. N. Chaudhari“"A Novel Sliding Mode Controller for Induction Motor DTC Drive with Smooth Performance" IEEE PEDS 2011, Singapore, 5 - 8 December 2011

[15] Hadda Benderradji,Adessalam Makouf “ Sliding Mode Linearization Control of Induction Motor Using a Sliding Mode Flux Observer" Mediamira Science, volume 51,Number 2, 2010

[16] Fizatul Aini Patakor,Marizan Sulaiman,Zulkifilie Ibrahim "Comparison Performance of Induction Motor Using SVPWM and Hysteresis Current Controller" Journal of Theoretical and Applied Information Technology, 15st August 2011. Vol. 30 No.1

[17] Mohamed M. ,Marwa .F ,’Decoupled Fuzzy Sliding Mode Control for a Synchronous Motor Speed Control" IJCA, volume 47- No 11, June 2012

[18] J.Soltani, G.R.Arab Markadeh, "A current based output feedback sliding mode control for speed sensor less induction motor machine drive using adaptive sliding mode observer" PEDS 2003. 